presence of and in the absence of a 1-sec, 80-dB tone of the same frequency. Each data point in Fig. 1 is the geometric mean of the three Os' results. Two sensation magnitude functions were fitted to the data by the method of least squares. The finding that magnitude estimations for all amplitudes of the tactile stimulus, including zero amplitude, were higher when the tone was presented than when it was not presented supports the hypothesis that a brief auditory stimulus presented simultaneously with a tactile stimulus can enhance tactile sensations.

It should be pointed out, however, that sensory interaction as psychophysically measured is a labile phenomenon. The experimental procedure may have a variety of effects on the $O$. As determined by previous studies, auditory stimulation may change tactile sensitivity and it may induce $O$ to change his decision strategy. The results of the present study suggest that auditory stimulation may also change both the signal level and the noise level in the tactile sensory system, leaving sensitivity unchanged.

\section{REFERENCES}

Gescheider, G. A., Barton, W. G., Bruce, M. R., Goldberg, J. M., \& Greenspan, M. J. The effects of simultaneous auditory stimulation upon the detection of tactile stimuli. Journal of Experimental Psychology, 1969, 81, 120-125.

Gescheider, G. A. Herman, D. D., \& Phillips, J. N. Criterion shifts in the measurement of tactile masking. Perception \& Psychophysics, $1970,8,433-436$.

Gescheider, G. A., \& Niblette, R. K. Cross-modality masking for touch and hearing. Journal of Experimental Psychology, $1967,74,313-320$.

Green, D. M., \& Swets, J. A. Signal detection theory and psychophysics. New York: Wiley, 1966.

Theodor, L. H. A neglected parameter: Some comments on "A table for calculation of $d^{\prime}$ and $\beta$." Psychological Bulletin, $1972,78,260-261$.

(Received for publication November 9, 1973.)

\title{
Reinforcement relation: Reversibility within daily experimental sessions
}

\author{
JOSÉ J. BAUERMEISTER \\ University of Puerto Rico, Rio Piedras, Puerto Rico 00931 \\ and \\ ROBERT W. SCHAEFFER \\ Auburn University, Auburn, Alabama 36830
}

\begin{abstract}
Running and licking response probabilities in rats were obtained for the first and last 13-min periods of 30-min daily test sessions. When licking was the more probable response, it reinforced running; when running was the more probable response, it reinforced licking. These data confirm the relative and reversible properties of the reinforcement relation.
\end{abstract}

Premack (1965, 1971) has conceptualized reinforcement as a relative relation between responses. This view contrasts with the traditional concept of reinforcement in which responses are classified absolutely as either reinforcing or nonreinforcing. A corollary of Premack's relativity hypothesis, that the reinforcement relation is reversible, was supported in an experiment with rats where differential probabilities of running and licking were produced, then subsequently reversed by manipulating the $\mathrm{Ss}^{\prime}$ accessibility to an 
Table 1

Summary of Experimental Design and Number of Sessions for Each Animal

\begin{tabular}{|c|c|c|c|c|c|c|}
\hline \multirow[b]{2}{*}{ Phase } & \multicolumn{3}{|c|}{ Experimental Condition in Each Session } & \multicolumn{3}{|c|}{ Number of Sessions } \\
\hline & $\begin{array}{c}\text { Subsession I } \\
\text { (First 13 Min) } \\
\end{array}$ & $\begin{array}{l}\text { Intersubsession } \\
\text { (4 Min) }\end{array}$ & $\begin{array}{r}\text { Subsession II } \\
\text { (Last 13 Min) } \\
\end{array}$ & S1 & S4 & S8 \\
\hline I & Paired Free Operant & Paired Free Operant & Paired Free Operant & 18 & 18 & 18 \\
\hline II & Run-to-Lick & Paired Free Operant & Paired Free Operant & 20 & 14 & 14 \\
\hline III & Run-to-Lick & Paired Free Operant & Lick-to-Run & 32 & 34 & 44 \\
\hline IV & Run-to-Lick & Paired Free Operant & Paired Free Operant & 14 & 12 & 8 \\
\hline V & Paired Free Operant & Paired Free Operant & Paired Free Operant & 10 & 10 & 8 \\
\hline
\end{tabular}

activity wheel and water (Premack, 1962). In the first part of Premack's study, water was continuously available and running was made more probable than licking by restricting the Ss' access to an activity wheel to only $1 \mathrm{~h}$ per day. A lick-to-run contingency was then arranged in which each five licks made the wheel available for $10 \mathrm{sec}$. As expected, the more probable running response reinforced the licking response. During the second part of Premack's experiment, licking was made more probable than running by providing free access to the activity wheel and by restricting the Ss' access to water to $1 \mathrm{~h}$ per day, then five instrumental runs were required to make the drinking tube available for a $10-\mathrm{sec}$ period. Under these conditions the more probable licking response reinforced the running response, thereby demonstrating reversibility of the reinforcement relation, between sessions, with the same Ss.

Is it possible to obtain a reversal of the reinforcement relation within each daily session? Preliminary data collected by Bauermeister (1970) indicated that the probabilities of licking and running, in 23-h-water-deprived rats, showed progressive within-session changes when the opportunities to run and to drink were both freely and concurrently available. Although the probability of drinking was greater than the probability of running during the first $13 \mathrm{~min}$ of a 30 -min daily session, the probabilities of occurrence of these responses during the last $13 \mathrm{~min}$ of the daily session were reversed. These within-session alterations in response probabilities provided the stimulus for the present experiment, which was a test of Premack's reversibility hypothesis within each daily session.

\section{METHOD}

Three female albino rats, 180 days old at the beginning of the experiment, and under a 23-h-water-deprivation schedule, served as Ss.

Three activity chambers described in detail by Schaeffer (1966) were used. The chambers permitted the presentation and retraction of a drinking tube and the braking and freeing of the activity wheel. The drinking tube in the activity chambers contained a $4 \%$, by weight, sucrose solution. The running and licking responses were recorded by counters and Esterline-Angus digital operations recorders.

The experiment was conducted in five phases. Table 1 summarizes the experimental design and the number of 30 -min daily sessions given each $\mathrm{S}$. The total number of sessions given each $\mathrm{S}$ depended solely upon stabilization of the running and licking responses across sessions. Throughout the experiment, each 30-min daily session was divided into three subsessions: Subsession I (the first $13 \mathrm{~min}$ ), Subsession II (the last $13 \mathrm{~min}$ ), and an Intersubsession 4-min period which separated the off set of Subsession I from the onset of Subsession II.

During Phase I, a paired free operant (PFO) condition (running and licking freely and concurrently available) was employed in Subsession I, Subsession II, and the intersubsession interval to permit estimation of running and licking response probabilities for each subsession. The PFO interval that separated Subsessions I and II provided the Ss with free access to the sucrose solution and the wheel following Subsession I, and ensured a higher probability of running than licking in Subsession II. As is indicated in Table 1, thie PFO condition during the 4-min intersubsession interval was maintained in each of the experimental phases throughout the entire experiment.

During Phase II, when the run-to-lick contingency was arranged in Subsession I [each completion of 12 (360 deg) wheel turns made the drinking tube available for $10 \mathrm{sec}$, the PFO condition was continued during Subsession II. The purpose of these procedures in Phase II was to determine whether the licking and running response probabilities that had been obtained during the PFO condition in Subsession II in Phase I, would be altered by the introduction of the run-to-lick contingency in Subsession I of Phase II.

Phase III constituted the critical phase of the experiment. As indicated in Table 1, the run-to-lick contingency in Subsession I was continued, as was the PFO condition during the 4-min intersubsession period. In Subsession II in Phase III, the drinking tube was freely available, but the activity wheel was braked, and a lick-to-run contingency was programmed so that each completion of 12 licks was followed by a 10-sec period of wheel availability. Phases IV and V constituted direct replications of Phases II and I, respectively.

\section{RESULTS AND DISCUSSION}

Table 2 presents the mean number of runs (180-deg wheel turns) and licks for each S during the last 6 days of Subsessions I and II, for Phases I, II, III, IV, and V. The table shows that for each $\mathrm{S}$, the sucrose-licking response was more probable than the running response during the PFO condition in Subsession I of Phase I. This numerical response relation was confirmed by analyses of response durations: mean times spent licking and running by the three Ss during the last 6 days in Subsession I of Phase I were 283.97 and $228.09 \mathrm{sec}$, respectively. Running, however, was a more probable response than licking in Subsession II of Phase I. Mean times spent running and licking by the three animals during Subsession II (last 6 days) in Phase I were 347.19 and $20.26 \mathrm{sec}$, respectively. The data in Table 2 show 
Table 2

Mean Number of Runs (180-Deg Wheel Turns) and Licks During the Last 6 Days in Subsessions I and II Under Experimental Phases I-V

\begin{tabular}{|c|c|c|c|c|c|c|c|}
\hline Interval & Rat & Response & Phase I & Phase II & Phase III & Phase IV & Phase V \\
\hline \multirow{3}{*}{ Subsession I } & $\mathrm{S} 1$ & $\begin{array}{l}\text { Runs } \\
\text { Licks }\end{array}$ & $\begin{array}{r}602.16 \\
1771.77\end{array}$ & $\begin{array}{r}695.33 \\
1506.83\end{array}$ & $\begin{array}{r}697.66 \\
1576.50\end{array}$ & $\begin{array}{r}720.16 \\
1818.33\end{array}$ & $\begin{array}{r}428.82 \\
1940.77\end{array}$ \\
\hline & S4 & $\begin{array}{l}\text { Runs } \\
\text { Licks }\end{array}$ & $\begin{array}{r}511.82 \\
1964.50\end{array}$ & $\begin{array}{r}760.50 \\
1507.33\end{array}$ & $\begin{array}{r}882.00 \\
1783.33\end{array}$ & $\begin{array}{r}898.50 \\
1572.00\end{array}$ & $\begin{array}{r}681.72 \\
1952.41\end{array}$ \\
\hline & $\mathrm{S} 8$ & $\begin{array}{l}\text { Runs } \\
\text { Licks }\end{array}$ & $\begin{array}{r}622.49 \\
1801.15\end{array}$ & $\begin{array}{r}874.55 \\
1692.16\end{array}$ & $\begin{array}{r}829.00 \\
1641.00\end{array}$ & $\begin{array}{r}844.83 \\
1762.83\end{array}$ & $\begin{array}{r}423.49 \\
2394.99\end{array}$ \\
\hline \multirow{3}{*}{ Subsession II } & $\mathrm{S} 1$ & $\begin{array}{l}\text { Runs } \\
\text { Licks }\end{array}$ & $\begin{array}{r}741.31 \\
97.83\end{array}$ & $\begin{array}{l}773.16 \\
167.51\end{array}$ & $\begin{array}{l}317.75 \\
856.66\end{array}$ & $\begin{array}{l}671.81 \\
164.91\end{array}$ & $\begin{array}{l}781.82 \\
268.00\end{array}$ \\
\hline & S4 & $\begin{array}{l}\text { Runs } \\
\text { Licks }\end{array}$ & $\begin{array}{l}758.50 \\
264.94\end{array}$ & $\begin{array}{r}793.30 \\
31.66\end{array}$ & $\begin{array}{l}202.66 \\
280.50\end{array}$ & $\begin{array}{r}990.00 \\
22.30\end{array}$ & $\begin{array}{r}969.58 \\
96.66\end{array}$ \\
\hline & S8 & $\begin{array}{l}\text { Runs } \\
\text { Licks }\end{array}$ & $\begin{array}{r}999.98 \\
32.31\end{array}$ & $\begin{array}{r}1053.29 \\
135.33\end{array}$ & $\begin{array}{l}160.33 \\
587.00 \\
\end{array}$ & $\begin{array}{r}954.48 \\
34.32 \\
\end{array}$ & $\begin{array}{r}1033.66 \\
54.28 \\
\end{array}$ \\
\hline
\end{tabular}

that the run-to-lick contingency in Subsession I in Phase II resulted in increased running and decreased licking, relative to the running and licking rates obtained in Subsession I of Phase I. The contingency in Subsession I of Phase II did not significantly alter the relationship between running and licking that was established in Subsession II of Phase I. Mean times spent running and licking by the three Ss during Subsession II in Phase II were 363.85 and $17.15 \mathrm{sec}$, respectively.

During Phase III, the run-to-lick contingency in Subsession I maintained responding as effectively as it had in Subsession I of Phase II. Analysis of the Subsession I Esterline-Angus records for each $S$ in Phase III indicated that, as in Phase II, a run-to-lick response pattern was developed in which completion of the scheduled running requirement was followed by licking during the $10 \mathrm{sec}$ of drinking tube availability. During Subsession II of Phase III, the lick-to-run contingency resulted in an increment in instrumental licking and a decrement in contingent running, relative to PFO licking and running rates obtained in Subsession II in Phase II. Visual observation and analysis of Subsession II Esterline-Angus records indicated that a lick-to-run response pattern was adopted by $\mathrm{Ss}$ in which each completion of the FR 12 lick requirement was followed by running during each 10 -sec period of wheel availability. Thus, during Phase III, the more probable licking response reinforced the less probable running response in Subsession I; in Subsession II, the more probable running response reinforced the less probable licking response. The group mean increment in running in Subsession I during Phase III was 39\% greater than mean PFO Subsession I running during Phase I. The group mean increment in Subsession II licking during Phase III was $415 \%$ greater than the mean PFO subsession licking during Phase II.

Phases IV and V constituted replications of Phases II and $I$, respectively. It is evident from Table 2 that the mean licking and running observed in Subsessions $I$ and II of Phases IV and V replicated the data obtained during the corresponding subsessions of Phases II and I, respectively.

The findings of the present study corroborate Premack's $(1965,1971)$ contentions regarding the relativity and reversibility of the reinforcement relation. Unlike Premack's (1962) study, in which probabilities of running and licking were reversed across sessions by manipulating S's access to an activity wheel, in the present study the probabilities of the two responses were left to undergo natural preferential response alterations characteristic of unrestrained behavior patterns that occur outside laboratory restrictions. Independently of the potential appropriateness of the baseline technique of allowing response probabilities to be expressions of the individual Ss' reactivity and preferences, rather than simple products of experimental manipulations, the present results emphasize the importance of careful identification of momentary response probabilities. This is of crucial predictive importance to the reinforcement analyst who might fail to recognize that average overall sessional response probabilities may represent gross miscalculations of momentary within-session probabilities, and misidentification of appropriate and predictive contingencies of reinforcement, as has been acknowledged previously by Bauermeister (1970) and Premack (1971).

\section{REFERENCES}

Bauermeister, J. J. Positive reinforcement: Further tests of the Premack theory. Unpublished doctoral dissertation, Florida State University, 1970.

Premack, D. Reversibility of the reinforcement relation. Science,

1962, 136, 255-257.
Premack, D. Reinforcement theory. In D. Levine (Ed.), Nebraska symposium on motivation, 1965. Lincoln: University of Nebraska Press, 1965. Pp. 123-180.

Premack, D. Catching up with common sense or two sides of a generalization: Reinforcement and punishment. In R. Glaser (Ed.), The nature of reinforcement. New York: Academic Press, 1971. Pp. 121-150.

Schaeffer, R. W. A new device for programming contingencies between drinking, running, and lever pressing. Journal of the Experimental Analysis of Behavior, 1966, 9, 529-533.

(Received for publication December 7, 1973.) 